CARDIOVASCULAR MEDICINE

\title{
Trends in reperfusion therapy of ST segment elevation myocardial infarction in Switzerland: six year results from a nationwide registry
}

\author{
A-A Fassa, P Urban, D Radovanovic, N Duvoisin, J-M Gaspoz, J-C Stauffer, P Erne, for the AMIS \\ Plus Investigators
}

Heart 2005;91:882-888. doi: 10.1136/hrt.2004.037689

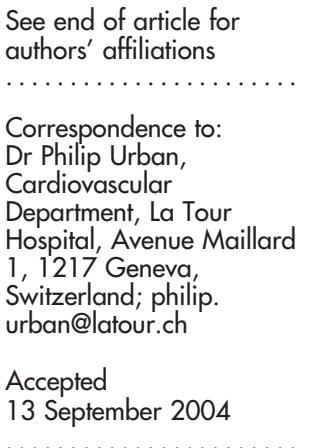

Objective: To document the trends in reperfusion therapy for ST segment elevation myocardial infarction (STEMI) in Switzerland.

Design: National prospective multicentre registry, AMIS Plus (acute myocardial infarction and unstable angina in Switzerland), of patients admitted with acute coronary syndromes.

Setting: 54 hospitals of varying size and capability in Switzerland.

Patients: 7098 of 11845 AMIS Plus patients who presented with ST segment elevation or left bundle branch block on the ECG at admission.

Main outcome measures: In-hospital mortality and its predictors at admission by multivariate analysis. Results: The proportion of patients treated by primary percutaneous coronary intervention (PCI) progressively increased from 1997 to 2002, while the proportion with thrombolysis or no reperfusion decreased (from $8.0 \%$ to $43.1 \%$, from $47.2 \%$ to $25.6 \%$, and from $44.8 \%$ to $31.4 \%$, respectively). Overall in-hospital mortality decreased over the study period from $12.2 \%$ to $6.7 \%$ ( $p<0.001$ ). Main in-hospital mortality predictors by multivariate analysis were primary $\mathrm{PCl}$ (odds ratio (OR) $0.52,95 \%$ confidence interval (CI) 0.33 to 0.81 ), thrombolysis (OR $0.63,95 \% \mathrm{Cl} 0.47$ to 0.83 ), and Killip class III (OR 3.61, $95 \%$ $\mathrm{Cl} 2.49$ to 5.24 ) and class IV (OR 5.97, $95 \% \mathrm{Cl} 3.51$ to 10.17) at admission. When adjusted for the year, multivariate analysis did not show $\mathrm{PCl}$ to be significantly superior to thrombolysis for in-hospital mortality (OR 1.2 for $\mathrm{PCl}$ better, $95 \% \mathrm{Cl} 0.8$ to $1.9, \mathrm{p}=0.42$ ).

Conclusion: Primary PCl has become the preferred mode of reperfusion for STEMI since 2002 in Switzerland, whereas use of intravenous thrombolysis has decreased from 1997 to 2002 . Furthermore, there was a major reduction of in-hospital mortality over the same period.
S ince it was found in the mid 1970s that acute myocardial infarction resulted from a ruptured atherosclerotic plaque, causing thrombosis and occlusion of a coronary artery, ${ }^{1}$ and that restoration of flow salvages myocardium, major attention has been focused on reperfusion therapy. Several studies have documented the survival benefit provided by a thrombolytic, first by intracoronary administration and later intravenously. ${ }^{2-5}$ Numerous randomised controlled trials soon followed comparing intravenous thrombolysis with mechanical reperfusion by primary percutaneous coronary intervention (PCI). A meta-analysis of 23 randomised controlled trials comparing these two modes of reperfusion in ST segment elevation myocardial infarction (STEMI) showed a greater benefit associated with primary PCI in terms of short and long term mortality, non-fatal reinfarction, and stroke. ${ }^{6}$

On the basis of this information, national and international societies of cardiology have established guidelines concerning the management of STEMI. ${ }^{78}$ To assess how these translate into the "real world" of daily clinical practice, several short and long term registry based studies have been conducted. ${ }^{9-15}$

Since January 1997, a national prospective registry of hospital admissions for acute coronary syndromes called AMIS Plus (acute myocardial infarction and unstable angina in Switzerland) has been ongoing in Switzerland, with 54 of the 106 hospitals treating STEMI in Switzerland now enrolling patients. We used the opportunity offered by this registry to analyse the current management of acute myocardial infarction in Switzerland, as well as trends over time, as a way to assess the impact of guidelines and major randomised controlled trials on everyday practice in Switzerland.

\section{METHODS}

The AMIS Plus project is a nationwide prospective registry of patients admitted with acute coronary syndromes to hospitals in Switzerland. The registry began in 1997 and has since then been recruiting patients. At the time of the present analysis, 54 of the 106 hospitals treating STEMI in Switzerland, ranging from community institutions to large tertiary facilities, were enrolling patients. Participating centres provide blinded data for each patient through a standardised internet or paper based questionnaire. The data are centralised at the Institute of Social and Preventive Medicine at the University of Zurich, where the data are checked for plausibility and consistency and incomplete questionnaires are returned to the enrolment centres for completion. The registry was approved by the Above-Regional Ethics Committee for Clinical Studies and the Swiss Board for Data Security. The AMIS Plus project is officially supported by the Swiss societies of cardiology, internal medicine, and intensive care medicine and is sponsored by

Abbreviations: AMIS Plus, acute myocardial infarction and unstable angina in Switzerland; CK, creatine kinase; MIR, myocardial infarction registry; MITRA, maximal individual therapy in acute myocardial infarction; NRMI 3, national registry of myocardial infarction 3; $\mathrm{PCl}$, percutaneous coronary intervention; STEMI, ST segment elevation myocardial infarction 


\begin{tabular}{|c|c|c|c|c|}
\hline & Patients* & $\begin{array}{l}\text { Primary PCI } \\
n=1419\end{array}$ & $\begin{array}{l}\text { Thrombolysis } \\
\mathrm{n}=\mathbf{2 8 3 3}\end{array}$ & $\begin{array}{l}\text { No reperfusion } \\
n=2846\end{array}$ \\
\hline Age (years) & $7035(99.1 \%)$ & $60.2(12.5)$ & $62.7(12.4)$ & $70.5(12.9) \dagger$ \\
\hline Women & $6997(98.6 \%)$ & $292(21.4 \%)$ & $650(23.3 \%)$ & $962(33.9 \%) \dagger$ \\
\hline History of CAD & $5106(71.9 \%)$ & $372(30.0 \%)$ & $516(28.6 \%)$ & $933(45.3 \%) \dagger$ \\
\hline Diabetes & $6890(97.1 \%)$ & $230(16.7 \%)$ & $428(15.6 \%)$ & $708(25.6 \%) \dagger$ \\
\hline Hypertension & $6834(96.3 \%)$ & $658(48.1 \%)$ & $1231(45.0 \%)$ & $1532(56.1 \%) \dagger$ \\
\hline Current smoker & $6716(94.6 \%)$ & $681(51.7 \%)$ & $1297(47.6 \%)$ & $865(32.3 \%) \dagger$ \\
\hline Hyperlipidaemia & $6476(93.3 \%)$ & $827(62.2 \%)$ & $1446(55.3 \%)$ & $1208(47.7 \%) \dagger$ \\
\hline \multicolumn{5}{|c|}{ Haemodynamic parameters at admission } \\
\hline $\begin{array}{l}\text { Heart rate (beats/min) } \\
\text { Systolic BP (mm Hg) }\end{array}$ & $\begin{array}{l}7046(99.3 \%) \\
7056(99.4 \%)\end{array}$ & $\begin{array}{l}77.1(19.5) \\
131.1(27.3)\end{array}$ & $\begin{array}{l}76.8(19.5) \\
136.0(26.8)\end{array}$ & $\begin{array}{l}84.4(24.7) \dagger \\
135.4(29.4) \dagger\end{array}$ \\
\hline Diastolic BP (mm Hg) & $7034(99.1 \%)$ & $77.6(17.3)$ & $80.5(18.0)$ & $78.6(18.8) t$ \\
\hline Killip class at admission & $6903(97.3 \%)$ & & & \\
\hline 1 & & $1119(80.3 \%)$ & $2138(77.7 \%)$ & $1684(61.1 \%) \dagger$ \\
\hline$\|$ & & $181(13.0) \%$ & $491(17.8 \%)$ & $699(25.4 \%) \dagger$ \\
\hline III & & $38(2.7 \%)$ & $79(2.9 \%)$ & $285(10.3 \%) \dagger$ \\
\hline IV & & $56(4.0 \%)$ & $44(1.6 \%)$ & $89(3.2 \%) \dagger$ \\
\hline \multicolumn{4}{|l|}{ ECG at admission } & $8: 30 \dagger$ \\
\hline ST elevation & $7081(99.8 \%)$ & $1373(96.8 \%)$ & 2802 (99.0\%) & $2453(86.6 \%) \dagger$ \\
\hline LBBB & $7046(99.3 \%)$ & $63(4.5 \%)$ & $109(3.9 \%)$ & $536(18.9 \%) \dagger$ \\
\hline Q wave & $7033(99.1 \%)$ & $374(26.4 \%)$ & 904 (32.2\%) & $1150(41.0 \%) \dagger$ \\
\hline \multicolumn{5}{|l|}{ Out of hospital management } \\
\hline CPR & $6907(97.3 \%)$ & $89(6.4 \%)$ & $113(4.1 \%)$ & $191(6.9 \%) \dagger$ \\
\hline DC shock & $6716(94.6 \%)$ & $81(6.5 \%)$ & $97(3.6 \%)$ & $110(4.0 \%) \dagger$ \\
\hline \multicolumn{5}{|c|}{$\begin{array}{l}\text { Values are number }(\%) \text { or mean }(S D) \text {. } \\
\text { *Patients for whom data were available; } t p<0.001 \text { across all three groups. } \\
\text { BP, blood pressure; CAD, coronary artery disease, including myocardial infarction, stable angina, ischaemia, } \\
\text { angioplasty, and coronary artery bypass; CPR, cardiopulmonary resuscitation; DC, defibrillation/cardioversion; } \\
\text { DSA, delay between symptom onset and admission to hospital; LBBB, left bundle branch block; PCl, percutaneous } \\
\text { coronary intervention. }\end{array}$} \\
\hline
\end{tabular}

unrestricted grants from the Swiss Heart Foundation as well as a number of pharmaceutical and medical device companies (listed in the acknowledgements).

The questionnaire comprises 140 items for each patient and is filled in by the coordinator of each institution. It seeks information regarding medical history and existing comorbidities, known cardiovascular risk factors, acute symptoms, out of hospital management, clinical presentation, early (first 48 hours) in-hospital management, reperfusion therapy, hospital course, diagnostic tests used or planned, hospital length of stay, and discharge medication and destination.

Patients are enrolled in the registry on the basis of their final diagnosis, which must comply with one of the three following definitions: acute myocardial infarction (symptoms or ECG changes compatible with acute coronary syndrome, or both, and cardiac enzymes (total creatine kinase (CK) or CK$\mathrm{MB}$ ) at least twice the upper limit of normal range); acute coronary syndrome with minimum necrosis (symptoms or ECG changes compatible with acute coronary syndrome, or both, and cardiac enzymes (total CK or CK-MB) lower than twice the upper limit of normal range, and positive troponins); and unstable angina (symptoms or ECG changes compatible with acute coronary syndrome, or both, and normal cardiac enzymes). Cases that are of unclear or noncardiac cause are not included.

\section{Patient selection}

The present analysis was based on patients satisfying the criteria for one of the three categories stated above and who were admitted with a suspected STEMI as an initial diagnosis. Therefore, we selected the patients from the 54 participating centres between January 1997 and December 2002 in the AMIS Plus registry who presented with ST segment elevation or a left bundle branch block on the admission ECG.

\section{Statistical analysis}

Data concerning patients were analysed according to the mode of reperfusion received: primary PCI, thrombolysis, and no reperfusion. Discrete variables are presented as absolute numbers and percentages and continuous variables are presented as mean (SD) or median. Group differences were compared by the non-parametric Pearson $\chi^{2}$ test for discrete data and by analysis of variance for continuous data. A probability value of $\mathrm{p}<0.05$ was considered significant.

A multivariate logistic regression model (backwards logistic regression method) was used to determine inhospital mortality predictors from the following set of variables: admission year; age; sex; systolic and diastolic blood pressures; heart rate; history of arterial hypertension; history of hyperlipidaemia; history of diabetes; current smoking status; cardiopulmonary resuscitation before admission; defibrillation/cardioversion before admission; Killip class at hospital admission (class I as reference category); delay between symptom onset and admission to hospital $>6$ hours; Q waves on initial ECG; left bundle branch block on initial ECG; ST segment elevation on initial ECG; thrombolysis ("no reperfusion" as reference category); and primary PCI ("no reperfusion" as reference category). Separate univariate logistical models were first fitted for each variable and then backwards elimination with a significance level of 0.05 was performed. Odds ratios were simultaneously adjusted for all the other predictors included in the multivariate logistic regression model. An additional logistic regression model was adjusted for the admission year to analyse whether the difference in in-hospital mortality between thrombolysis and PCI was an artefact in relation to the changes in reperfusion therapy.

SPSS (version 11.5, SPSS Inc, Chicago, Illinois, USA) was used for all statistical analyses. 


\section{RESULTS}

Between January 1997 and December 2002, the 54 participating centres enrolled 11845 patients admitted with an acute coronary syndrome in the AMIS Plus registry. Of these, 7279 patients presented with ST segment elevation or a left bundle branch block on the admission ECG. Data concerning reperfusion therapy were unclear or missing for 181 patients, who were therefore excluded. Thus, the present analysis was based on 7098 patients.

Table 1 shows patient demographics and characteristics on hospital admission according to the mode of reperfusion. These characteristics were similar in the patients who underwent primary PCI and thrombolysis in terms of age, sex, cardiovascular risk factors, and haemodynamic and ECG parameters. However, the patients who did not undergo reperfusion were older and had a higher rate of diabetes, hypertension, history of coronary artery disease, and haemodynamic instability at admission; more of them were women, they more often had a left bundle branch block on their admission ECG, and more important they had a longer delay from symptom onset to hospital admission. The questionnaire included an item on the reason why the patients did not undergo thrombolysis. When excluding the cases where PCI was preferred instead of thrombolysis (these patients were included in the primary PCI group), the information was available for $2224(78.1 \%)$ patients who did not receive any reperfusion. The main reasons were that these patients were admitted with too long a delay from their symptom onset $(52.1 \%)$, they did not have a certain diagnosis of STEMI, and they did not have the necessary ECG criteria $(28.7 \%)$. The remainder (19.2\%) either had a contraindication to thrombolysis or declined it.

Analysis of the proportion of patients treated with each mode of reperfusion from 1997 to 2002 (fig l) shows the progressive increase in the use of primary PCI as a mode of reperfusion throughout the study period $(p<0.001$ for trend). The proportion of patients who received thrombolysis and those who did not undergo any reperfusion gradually decreased over the same period ( $p<0.001$ for both trends). The proportion of patients undergoing each reperfusion mode and the calendar year in AMIS Plus and other registries (fig 2) shows that AMIS Plus is the first registry in which primary PCI has become the preferred mode of reperfusion for STEMI.
The overall in-hospital mortality for all patients throughout the study period was $10.1 \%$. The mortality of the patients who underwent primary PCI, thrombolysis, and no reperfusion was $4.1 \%, 5.7 \%$, and $17.4 \%$, respectively $(p<0.001)$. Furthermore, overall in-hospital mortality decreased significantly $(\mathrm{p}<0.001)$ over the study period (fig 3). In-hospital mortality stratified according to the mode of reperfusion also decreased significantly in the patients who were treated with primary PCI $(\mathrm{p}=0.032)$ and in those who did not undergo reperfusion therapy ( $\mathrm{p}=0.038$ ) from 1997 to 2002, whereas mortality did not evolve significantly in the patients treated with thrombolysis $(\mathrm{p}=0.095)$.

Table 2 gives results of multivariate analysis of predictors for in-hospital mortality with their odds ratios and 95\% confidence intervals based on 4993 patients (70.3\%). Of all variables included in the model, Killip classes III and IV, prehospitalisation cardiopulmonary resuscitation, and withholding both primary PCI and thrombolysis were the strongest predictors of in-hospital mortality. Furthermore, a regression model comparing in-hospital mortality between reperfusion therapies, adjusted for the admission year, did not show that PCI was significantly more beneficial than thrombolysis (odds ratio 1.2 for a lower mortality associated with PCI; 95\% confidence interval 0.76 to $1.90, \mathrm{p}=0.42$ ).

\section{DISCUSSION}

By including a significant number of the hospitals in Switzerland, the AMIS Plus registry gives an accurate picture of the contemporary management of acute coronary syndromes in this country. This ongoing multicentre project, which offers the possibility of both data input and data analysis over the internet, is a useful tool to monitor current practices and to assess the impact of major randomised controlled trials and guidelines. ${ }^{16}{ }^{17}$ The present analysis focused on the immediate reperfusion therapy of STEMI and its evolution over time.

The patients who underwent reperfusion, either by primary PCI or by thrombolysis, had a very similar profile. One notable difference was the delay between the onset of the symptoms and admission to hospital, which was about one hour longer for the patients who underwent primary PCI. Similar findings were described in the MIR (myocardial infarction registry) and MITRA (maximal individual therapy

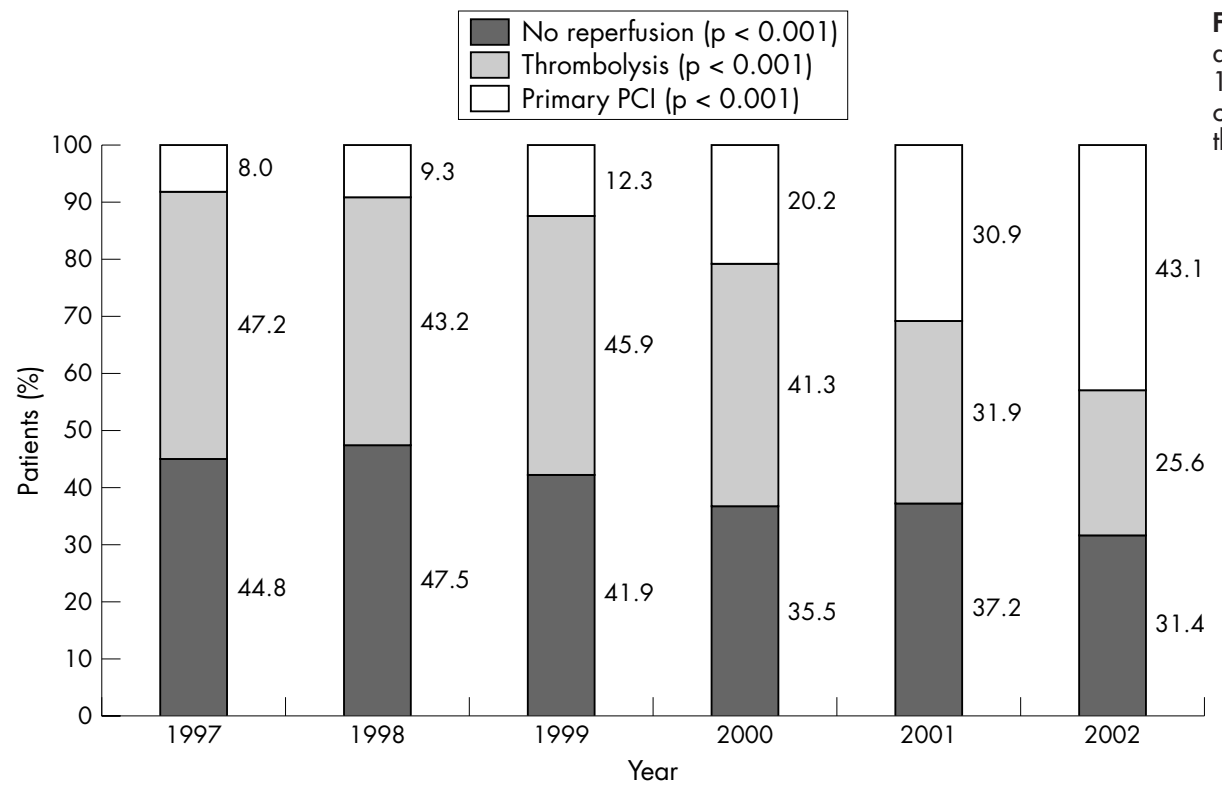

Figure 1 Proportion of patients according to reperfusion mode from 1997 to 2002 . $\mathrm{PCl}$, percutaneous coronary intervention; $p$ for trend over the time period. 


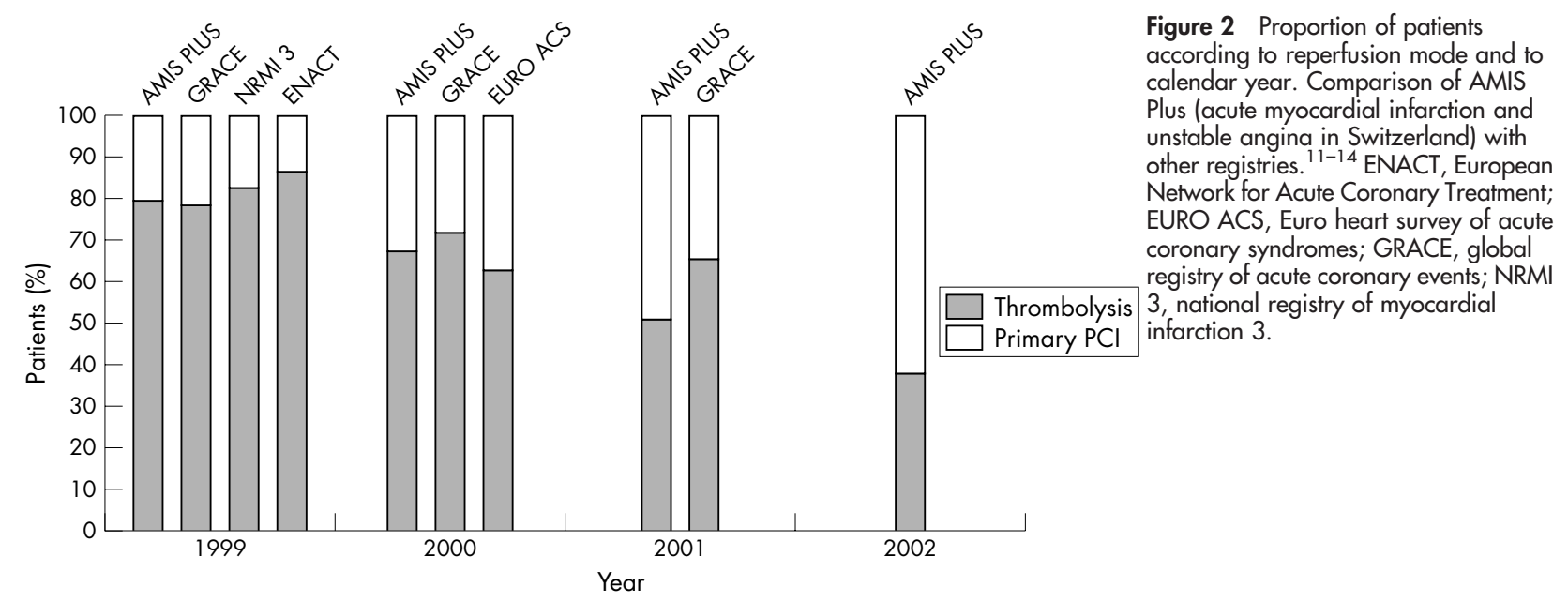

in acute myocardial infarction) registries ${ }^{9}$ and may be due to awareness that the beneficial effect of thrombolysis decreases with increasing pre-hospital delay. ${ }^{18}$ This effect does not apply to the same extent for primary PCI, ${ }^{19-21}$ therefore probably leading to a more liberal use of primary PCI for patients admitted late from the time of symptom onset.

The baseline characteristics were similar to the results of a previous study by Danchin and colleagues, ${ }^{10}$ which found no significant differences between the patients who underwent primary PCI and thrombolysis in terms of age, sex, and cardiovascular risk factors. The same study also showed that patients who did not undergo reperfusion were older and were admitted to hospital later. In our study, many of the differences in baseline characteristics between these patients and those who did undergo PCI or thrombolysis account for why those patients were not treated. Indeed, late arrival in hospital after symptom onset was noted to be the reason why about one half of these patients did not undergo reperfusion. Another reason stated was the unfulfilled ECG criteria, probably in relation to the higher rate of left bundle branch block and lower rate of ST segment elevation present on the initial ECG in these patients. In addition, the uncertainty of the diagnosis was also stated as a reason leading to absence of reperfusion. This may be linked, to a certain extent, to the higher proportion of women among these patients, who are known to have a higher incidence of atypical symptoms or silent myocardial infarctions than men, ${ }^{22-24}$ thus creating confusion regarding the establishment of a clear diagnosis. The higher age and therefore the higher rate of comorbidities among these patients may also have influenced the choice of not performing reperfusion. The integration of Charlson's index of co-morbidities in the questionnaire since

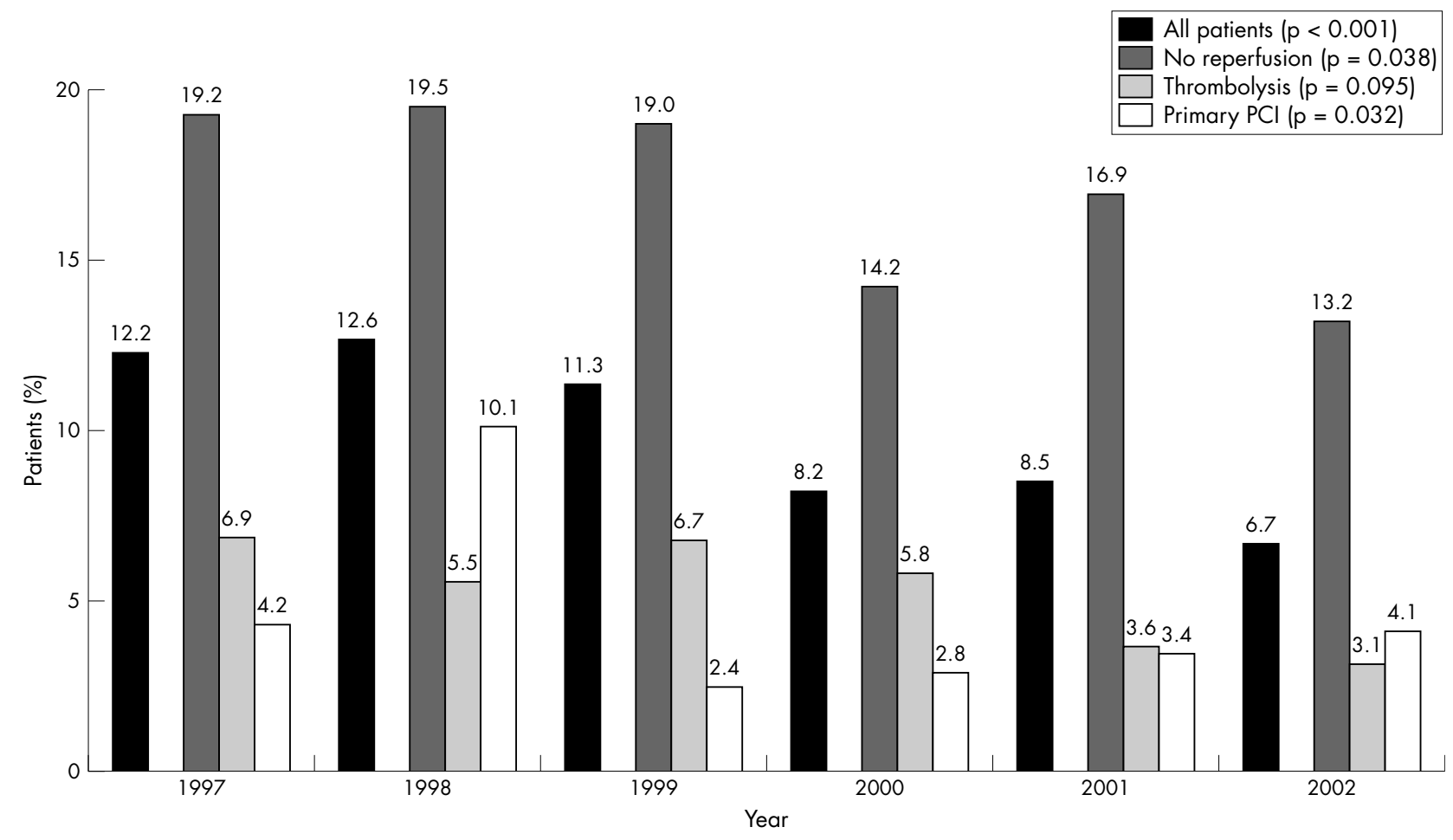

Figure 3 Evolution of in-hospital mortality for all AMIS Plus patients according to reperfusion mode from 1997 to 2002 ; $p$ for trend over the time period. 
Table 2 Multivariate analysis for predicting in-hospital mortality at admission ( $n=4993)$

\begin{tabular}{llll}
\hline & OR & $95 \%$ Cl for OR & p Value \\
\hline Primary PCl & 0.52 & 0.33 to 0.81 & 0.004 \\
Thrombolysis & 0.63 & 0.47 to 0.83 & 0.001 \\
Admission year (per additional year)* & 0.87 & 0.81 to 0.94 & $<0.001$ \\
Age (per additional year) & 1.07 & 1.06 to 1.08 & $<0.001$ \\
Female sex & 1.42 & 1.11 to 1.82 & 0.005 \\
Heart rate (per additional beat/min) & 1.011 & 1.006 to 1.015 & $<0.001$ \\
Systolic BP (per additional mm Hg) & 0.98 & 0.98 to 0.99 & $<0.001$ \\
Killip class II & 1.71 & 1.29 to 2.27 & $<0.001$ \\
Killip class III & 3.61 & 2.49 to 5.24 & $<0.001$ \\
Killip class IV & 5.97 & 3.51 to 10.17 & $<0.001$ \\
Q wave on ECG & 1.43 & 1.13 to 1.83 & $<0.001$ \\
Pre-hospital CPR & 3.02 & 1.98 to 4.59 & $<0.001$ \\
\hline *From 1997 to 2002. & & & \\
Cl, confidence interval; OR, odds ratio. & & &
\end{tabular}

$2002,{ }^{25}$ which was not used in the present analysis, should help us in the future to clarify further why any given patient is selected not to receive reperfusion. Furthermore, the proportion of patients who did not receive reperfusion significantly decreased from 1997 to 2002 (from $44.8 \%$ to $31.4 \%$ ). These results are comparable with those reported in registries that were conducted over the same period $(28.8 \%$ to $44.2 \%) .{ }^{11-14}$ Improvement of referral networks, as well as continuing efforts to decrease pre-hospital delays, should help to further reduce the proportion of these patients.

From 1997 to 2002, there was a major increase in the proportion of patients treated by primary PCI and therefore this procedure became the preferred mode of reperfusion for STEMI in 2002. Over the same period, the use of thrombolysis has gradually decreased. Although this trend has also been observed in other studies, ${ }^{11}{ }^{12}$ the AMIS Plus registry is, to our knowledge, the first to show that primary PCI has become the most frequently used means of reperfusion, ${ }^{11-14}$ certainly reflecting the impact of the results of several randomised controlled trials and guidelines for the management of STEMI, ${ }^{6-8}$ and showing that recent information is indeed being translated into clinical practice.

In AMIS Plus, the global in-hospital mortality for STEMI, regardless of whether reperfusion was carried out, was $10.1 \%$ during the six years of the study, which is comparable with that reported from NRMI 3 (national registry of myocardial infarction 3) $\left(9.8 \%\right.$ in 1999), ${ }^{10}$ but slightly higher than the results reported from other European and international multicentre studies $(6.0-8.0 \%){ }^{.12-14}$ This is probably explained by the fact that these studies either included a high proportion of academic medical centres with revascularisation facilities or had more selective inclusion criteria than in AMIS Plus (for example, excluding patients who died early in the emergency room, before admission to the coronary care unit). Moreover, our study shows a gradual decline of overall in-hospital mortality for STEMI, from $12.2 \%$ in 1997 to $6.7 \%$ in $2002(p<0.001)$. The evolution of in-hospital mortality stratified according to the reperfusion mode suggests that the decline of overall mortality during the study period was due to the simultaneous reduction of the mortality of patients who underwent PCI, as well as those who did not receive reperfusion, whereas there was no significant change in the mortality of the patients who underwent thrombolysis.

The overall in-hospital mortality during the study period associated with primary PCI and thrombolysis $(4.1 \%$ and $5.7 \%$, respectively) was similar to the results of previous registries and randomised trials. ${ }^{6}{ }^{10} 15$ A regression model comparing mortality between both reperfusion modes, adjusted for the admission year, did not show that primary PCI was significantly more beneficial than thrombolysis. However, the mortality associated with primary PCI significantly decreased over the study period, whereas the mortality associated with thrombolysis did not. This discordance has already been reported previously ${ }^{9}$ and is probably due to the fact that thrombolysis has not seen major advances over the past 10 years, whereas PCI has progressed greatly over the same period with the improvement of angioplasty technique, broader use of stents and glycoprotein IIb/IIIa inhibitors, growing experience of the treating physicians, and optimisation of out of hospital and in-hospital logistics to shorten door to balloon delays. ${ }^{20} 26-29$

The multivariate analysis for predicting in-hospital mortality at admission also confirmed the benefit associated with primary PCI and thrombolysis, contrasting with the results from previous studies. ${ }^{10}{ }^{15}$ Furthermore, admission year was a significant predictor, confirming the improvement in survival over the study period.

\section{Limitations}

Although at the time of this study 54 of the 106 hospitals treating STEMI in Switzerland were participating in the AMIS Plus registry, the number of the participating centres varied during the study period and they may therefore not be entirely representative of all the hospitals in the country. Thus, the absolute number of patients may not give a true picture of the national incidence of myocardial infarction leading to hospital admission. This should improve over the coming years as more centres join the project.

Another limitation, which is common to all registries, is that AMIS Plus is an observational study rather than a randomised trial. Some of the baseline characteristics of the patients were not available and may thus have created unrecognised bias. Nevertheless, although the participating centres were not individually audited on site, the data management centre continuously and carefully checked the data questionnaires and queried incomplete questionnaires as needed.

Lastly, it is important to mention that, although AMIS Plus is supported by unrestricted grants from several pharmaceutical and medical device companies, the data were collected and analysed independently. The sponsoring firms had no access to the raw data.

\section{Conclusions}

From 1997 to 2002, the use of reperfusion for STEMI has increased progressively in Switzerland, with primary PCI becoming the preferred mode of reperfusion since 2002. This shows that the information from randomised controlled trials and guidelines is adequately reshaping daily clinical practice for the management of STEMI. ${ }^{6-8}$ Along with this progression, in-hospital mortality decreased greatly over the same period. However, about one third of the patients still did not receive reperfusion therapy in 2002. A continued effort is therefore necessary to make reperfusion available to a greater 
proportion of patients with STEMI, in particular to those admitted late after symptom onset.

Moreover, at a time when modern cardiology is changing rapidly, with new strategies such as transferring patients for primary PCI and evaluating facilitated $\mathrm{PCI}^{21}{ }^{20-33}$ registries such as AMIS Plus should help us to assess the applicability and effectiveness of these potential changes to come and to contribute to improved care for patients with STEMI.

\section{ACKNOWLEDGEMENTS}

The AMIS Plus registry is funded by unrestricted grants from the Swiss Heart Foundation and from Astra-Zeneca AG, Biotronik AG, Bristol-Myers Squibb, Guidant AG, Johnson \& Johnson AG-Cordis Division, A Menarini AG, Merck Sharp \& Dohme-Chibret AG, Pfizer AG, Rahn AG, Roche Pharma AG, Sanofi-Synthélabo SA, and Takeda Pharma AG, all in Switzerland. This support is gratefully acknowledged. The supporting institutions did not have any role in the design of the registry or in data collection, analysis, or interpretation. The authors also gratefully thank Professor Burkhardt Siefert from the Institute of Social and Preventive Medicine, Zurich, for his assistance with the statistical analysis.

\section{Authors' affiliations}

A-A Fassa, P Urban, Cardiovascular Department, La Tour Hospital, Geneva, Switzerland

D Radovanovic, N Duvoisin, Institute of Social and Preventive Medicine, Zurich University, Zurich, Switzerland

J-M Gaspoz, Department of Internal Medicine, Geneva University Hospitals, Geneva, Switzerland

J-C Stauffer, Division of Cardiology, Centre Hospitalier Universitaire Vaudois, Lausanne, Switzerland

P Erne, Division of Cardiology, Kantonsspital, Lucerne, Switzerland

\section{APPENDIX}

\section{STEERING COMMITTEE}

P Erne, President, Lucerne; F W Amann, Zurich; W Angehrn, St Gallen; O Bertel, Zurich; J-M Gaspoz, Geneva; S Dehler, Zurich; F R Eberli, Zurich; F Gutzwiller, Zurich; P Hunziker, Basel; M Maggiorini, Zurich; B Quartenoud, Fribourg; J Schilling, Zurich; P Siegrist, Zollikerberg; J-C Stauffer, Lausanne; P Urban, Geneva; S Windecker, Bern.

\section{DATA MANAGEMENT CENTRE}

J Schilling, D Radovanovic, N Duvoisin, A Taskin, J Keller, J Piket-Stähelin.

\section{PARTICIPATING CENTRES}

The following hospitals participated in the AMIS Plus Registry, on which this report from 1997-2002 is based (in alphabetical order): Kantonsspital, Altdorf (Dr R Simon); Kantonales Spital Altstätten, Altstätten (Dr P-J Hangartner); Kantonsspital, Basel (PD Dr P Hunziker); St Claraspital, Basel (Dr C Grädel); Inselspital, Bern (Prof B Meier); Spitalzentrum Biel, Biel (Dr H Schläpfer); Oberwalliser Kreisspital, Brig-Glis (Dr D Evéquoz); Spital Bülach, Bülach (Dr R Pampaluchi, Dr A Ciurea); Rätisches Kantons- und Regionalspital Chur, Chur (Dr P Müller); Kreuzspital, Chur (Dr V Wüscher); Spital Davos, Davos Platz (Dr G Niedermaier); Hôpital cantonal Fribourg, Fribourg (Dr B Quartenoud); Spital Frutigen, Frutigen (Dr S Moser); HUG, Geneva (Dr J-M Gaspoz); Kantonsspital, Glarus (Dr W Wojtyna); Spital Grenchen, Grenchen (Dr P Schlup, Dr A. Oestmann); Bezirksspital Grosshöchstetten, Grosshöchstetten (Dr C Simonin); Kantonales Spital, Heiden (Dr R Waldburger); Kantonales Spital, Herisau (Dr P Staub); Spital Interlaken, Interlaken (Dr P Sula); Spital, Jegenstorf (Dr H Marty); Hôpital La Chaux-de-Fonds, La Chaux-de-Fonds (Dr H Zender); Spital Lachen, Lachen (Dr I Poepping); Kantonsspital, Lucerne (Prof P Erne); Hôpital régional, Martigny (Dr B Jordan); Hôpital de la Tour, Meyrin (PD Dr P Urban); Hôpital du Chablis, Monthey (Dr P Feraud); Hôpital de Zone, Montreux (Dr E Beretta); Hôpital du Jura bernois, Moutier (Dr C Stettler); Regionales Spital Zentrum, Münsingen (Dr F Repond); Kreisspital für das Freiamt, Muri (Dr A Spillmann); Groupement Hospitalier de l'Ouest Lémanique, Nyon (Dr R Polikar); Gesundheitszentrum Fricktal, Regionalspital Rheinfelden, Rheinfelden (Dr H-U Iselin); Kantonales Spital, Rorschach (Dr M Pfister); Kantonsspital Obwalden, Sarnen (Dr T Kaeslin); Kantonsspital Schaffhausen, Schaffhausen (Dr R Frey); Spital Limmattal, Schlieren (Dr B Risti); Spital Schwyz, Schwyz (Dr P Eichhorn); Ospidal d'Engiadina Bassa, Scuol (Dr G Flury, Dr C Neumeier); Bürgerspital, Solothurn (Dr P Hilti); Kantonsspital, St Gallen (Dr W Angehrn); Thusis Krankenhaus, Thusis (Dr U-P Veragut); Spital Uster, Uster (Dr D Maurer, Dr S Heinbuch); Kantonales Spital Uznach, Uznach (Dr A Weber); Spital Zimmerberg, Wädenswil (Dr G Garzoli); GZO Spital Wetzikon, Wetzikon (Dr M Graber); Kantonsspital, Winterthur (Dr A Haller); Kantonales Spital SurseeWolhusen, Wolhusen (Dr M Peter); Spital Zofingen, Zofingen (Dr H J Vonesch); Spital Zollikerberg, Zollikerberg (Dr P Siegrist); Zuger Kantonsspital, Zug (Prof M Vogt); Universitätsspital, Zurich (PD Dr $\mathrm{F}$ Eberli, $\mathrm{PD}$ Dr $\mathrm{M}$ Maggiorini); Stadtspital Triemli, Zurich (Prof O Bertel); Stadtspital Waid, Medizinische Klinik, Zurich (Dr M Brabetz, Dr S Christen).

\section{REFERENCES}

1 Davies MJ, Woolf N, Robertson WB. Pathology of acute myocardial infarction with particular reference to occlusive coronary thrombi. Br Heart J 1976;38:659-64.

2 Chazov El, Matveeva LS, Mazaev AV, et al. [Intracoronary administration of fibrinolysin in acute myocardial infarct]. Ter Arkh 1976;48:8-19.

3 Rentrop KP, Blanke H, Karsch KR, et al. Acute myocardial infarction: intracoronary application of nitroglycerin and streptokinase. Clin Cardiol 1979;2:354-63.

4 GISSI Investigators. Gruppo Italiano per lo Studio della Streptochinasi nell'Infarto Miocardico (GISSI). Effectiveness of intravenous thrombolytic treatment in acute myocardial infarction. Lancet 1986;i:397-402.

5 ISIS-2 Collaborative Group. Randomised trial of intravenous streptokinase, oral aspirin, both, or neither among 17187 cases of suspected acute myocardial infarction: ISIS-2, Lancet 1988;ii:349-60.

6 Keeley EC, Boura JA, Grines CL. Primary angioplasty versus intravenous thrombolytic therapy for acute myocardial infarction: a quantitative review of 23 randomised trials. Lancet 2003:361:13-20.

7 Ryan TJ, Antman EM, Brooks NH, et al. 1999 update: ACC/AHA guidelines for the management of patients with acute myocardial infarction. A report of the American College of Cardiology/American Heart Association task force on practice guidelines (Committee on Management Of Acute Myocardial Infarction). J Am Coll Cardiol 1999;34:890-911.

8 Van de Werf F, Ardissino D, Betriu A, et al. Management of acute myocardial infarction in patients presenting with ST-segment elevation. The task force on the management of acute myocardial infarction of the European Society of Cardiology. Eur Heart J 2003;24:28-66.

9 Zahn R, Schiele R, Schneider S, for the Maximal Individual Therapy in Acute Myocardial Infarction (MITRA) and the Myocardial Infarction Registry (MIR) Study Groups, et al. Decreasing hospital mortality between 1994 and 1998 in patients with acute myocardial infarction treated with primary angioplasty but not in patients treated with intravenous thrombolysis. Results from the pooled data of the maximal individual therapy in acute myocardial infarction (MITRA) registry and the myocardial infarction registry (MIR). J Am Coll Cardiol 2000:36:2064-71.

10 Danchin N, Vaur L, Genès N, et al. Treatment of acute myocardial infarction by primary coronary angioplasty or intravenous thrombolysis in the "real world". One-year results from a nationwide French survey. Circulation 1999;99:2639-44

11 Rogers WJ, Canto JG, Lambrew CT, et al, for the investigators in the national registry of myocardial infarction 1,2 and 3. Temporal trends in the treatment of over 1.5 million patients with myocardial infarction in the US from 1990 through 1999. The national registry of myocardial infarction 1, 2 and 3. J Am Coll Cardiol 2000;36:2056-63.

12 Fox KAA, Goodman SG, Anderson FA, on behalf of the GRACE Investigators, et al. From guidelines to clinical practice: the impact of hospital and geographical characteristics on temporal trends in the management of acute coronary syndromes. The global registry of acute coronary events (GRACE). Eur Heart J, 2003;24;1414-24.

13 Fox KAA, Cokkinos DV, Deckers J, on behalf of the ENACT (European Network for Acute Coronary Treatment) investigators, et al. The ENACT study: 
a pan-European survey of acute coronary syndromes. Eur Heart $J$ 2000;21:1440-9.

14 Hasdai D, Behar S, Wallentin L, et al. A prospective survey of the characteristics, treatments and outcomes of patients with acute coronary syndromes in Europe and the Mediterranean basin. The Euro heart survey of acute coronary syndromes (Euro heart survey ACS). Eur Heart J 2002; 23:1190-201

15 Every NR, Parsons LS, Hlatky M, et al. A comparison of thrombolytic therapy with primary coronary angioplasty for acute myocardial infarction. N Engl J Med 1996;335:1253-60.

16 Urban P, Bernstein MS, Costanza MC, et al. An internet-based registry of acute myocardial infarction in Switzerland. Kardiovask Med 2000;3:430-40.

17 Erne $P$, Radovanovic D, Urban $P$, et al. Early drug therapy and in-hospital mortality following acute myocardial infarction. Heart Drug 2003;3:134-40.

18 Fibrinolytic Therapy Trialists' Collaborative Group. Indications for fibrinolytic therapy in suspected acute myocardial infarction: collaborative overview of early mortality and major morbidity results from all randomized trials of more than 1,000 patients. Lancet 1994;343:311-22.

19 Zahn R, Schiele R, Gitt AK, et al. Impact of prehospital delay on mortality in patients with acute myocardial infarction treated with primary angioplasty and intravenous thrombolysis. Am Heart J 2001;142:105-11.

20 Cannon CP, Gibson CM, Lambrew CT, et al. Relationship of symptom-onsetto-balloon time and door-to-balloon time with mortality on patients undergoing angioplasty for acute myocardial infarction. JAMA 2000;283:2941-57

21 Andersen HR, Nielsen TT, Rasmussen K, et al. A comparison of coronary angioplasty with fibrinolytic therapy in acute myocardial infarction. N Engl J Med 2003;349:733-42.

22 Kannel WB, Abbott RD. Incidence and prognosis of myocardial infarction in women: The Framingham Study. In: Eaker ED, Packard B, Wenger NK, et al. Coronary heart disease in women: proceedings of an NIH workshop. New York: Haymark Doyma, 1987:208-214.

23 Weaver WD, White HD, Wilcox RG, et al. Comparisons of characteristics and outcomes among women and men with acute myocardial infarction treated with thrombolytic therapy. JAMA 1996;275:777-82.
24 Tunstall-Pedoe $\mathbf{H}$, Morrison $\mathrm{C}$, Woodward $\mathrm{M}$, et al Sex differences in myocardial infarction and coronary deaths in the Scottish MONICA population of Glasgow 1985 to 1991. Presentation, diagnosis, treatment, and 28-day case fatality of 3991 events in men and 1551 events in women. Circulation 1996:93:1981-92

25 Charlson ME, Pompei P, Ales KL, et al. A new method of classifying prognostic comorbidity in longitudinal studies: development and validation. J Chronic Dis 1987; 40:373-83.

26 Stone GW, Brodie BR, Griffin JJ, et al. Clinical and angiographic follow-up after primary stenting in acute myocardial infarction. The primary angioplasty in myocardial infarction (PAMI) stent pilot trial. Circulation 1999;99:1548-54.

27 Suryapranata H, van't Hof AWJ, Hoorntje JCA, et al. Randomized comparison of coronary stenting with balloon angioplasty in selected patients with acute myocardial infarction. Circulation 1998:97:2502-5.

28 Montalescot G, Barragan P, Wittenberg O, et al. Platelet glycoprotein Ilb/Illa inhibition with coronary stenting for acute myocardial infarction. N Engl J Med 2001;344:1895-903.

29 Gaspoz JM, Unger PF, Urban P, et al. Impact of a public campaign on prehospital delay in patients reporting chest pain. Heart 1996;76:150-5.

30 Widimsky P, Budesinsky T, Vorac D, on behalf of the "PRAGUE" study group Investigators, et al. Long distance transport for primary angioplasty vs immediate thrombolysis in acute myocardial infarction. Final results of the randomised national multicentre trial-PRAGUE-2. Eur Heart J 2003;24:94-104

31 Hermann HC, Moliterno DJ, Ohman EM, et al. Facilitation of early percutaneous coronary intervention after reteplase with or without abciximab in acute myocardial infarction. Results from the SPEED (GUSTO-4 pilot) trial. J Am Coll Cardiol 2000:36:1489-96.

32 Keeley EC, Cigarroa J. Facilitated primary percutaneous transluminal coronary angioplasty for acute ST segment elevation myocardial infarction: rationale for reuniting pharmacologic and mechanical revascularization strategies. Cardiol Rev 2003;11:13-20.

33 Rux S, Lenssen K, Sonntag S, et al. Low hospital and long-term mortality in a prospective registry of facilitated percutaneous coronary intervention in acute myocardial infarction. Am J Cardiol 2003;92:67-71.

\section{IMAGES IN CARDIOLOGY}

\section{Cardiomyopathy induced by performance enhancing drugs in a competitive bodybuilder}

A 36 year old competitive bodybuilder presented with increasing dyspnoea on exertion over a six week period. He gave a 10 year history of use of anabolic steroids, growth hormone, ephedrine, and thyroxine. Echocardiography demonstrated severe left ventricular hypertrophy and systolic dysfunction. Serum ferritin was normal and there was no serological evidence of viral infection or connective tissue disease. Angiography revealed normal coronary arteries and cardiac magnetic resonance imaging (CMR) was performed to further investigate the cause of the cardiomyopathy. The left ventricle, shown here in end diastole (panel A) was noted to be severely hypertrophied (myocardial mass $465 \mathrm{~g}$; normal range $85-181 \mathrm{~g}$ ), dilated (end diastolic volume $319 \mathrm{ml}$; normal range 102 $235 \mathrm{ml})$, and systolic function was severely impaired (ejection fraction $20 \%)$. Imaging post administration of gadolinium-DTPA was negative for late enhancement (panel B), excluding both myocardial infarction and macroscopic evidence of myocardial fibrosis. Initial treatment has been commenced with a diuretic, angiotensin converting enzyme inhibitor, $\beta$ blocker, and anticoagula-
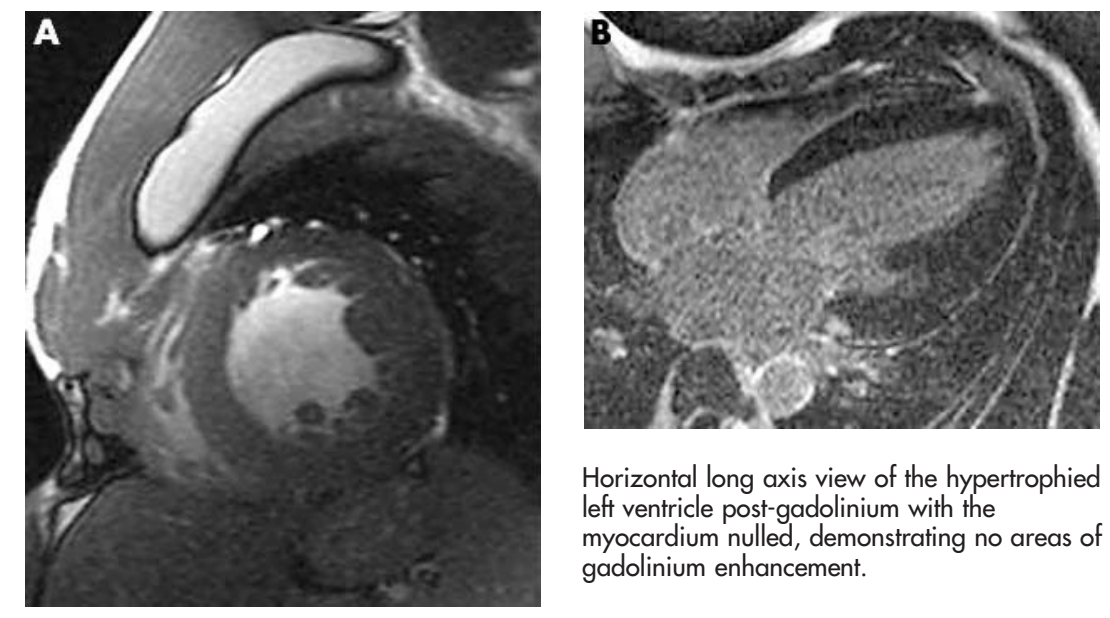

Horizontal long axis view of the hypertrophied left ventricle post-gadolinium with the myocardium nulled, demonstrating no areas of gadolinium enhancement.

Short axis view of the left ventricle in end diastole showing severe left ventricular hypertrophy and dilation as well as demonstrating an incidental pectoral implant, seen in the upper section of the image.

tion. Growth hormone excess has been associated with left ventricular hypertrophy while anabolic steroids have been associated both with myocardial hypertrophy, focal myocardial fibrosis, and premature myocardial infarction. Thyroxine may cause high output cardiac failure. CMR is the non-invasive investigation of choice in unexplained heart failure. This case illustrates that severe heart failure can occur in patients taking these performance enhancing drugs without CMR evidence of either myocardial infarction or myocardial fibrosis.

P B Mark

S Watkins

H J Dargie

pm124p@clinmed.gla.ac.uk 